\title{
A TRADUÇÃO INTERSEMIÓTICA DE HAMLET, POR MICHAEL ALMEREYDA
}

\section{Carmen Filgueiras}

\author{
Uma vez que não pode haver um Shakespeare \\ definitivo, recorro a diversos textos, em algumas \\ passagens alterando a pontuação, segundo $o$ \\ meu entendimento. \\ HAROLD BLOOM
}

Este artigo tem como objetivo analisar a adaptação cinematográfica da peça de Shakespeare, Hamlet, dirigida por Michael Almereyda. A tradução intersemiótica realizada pelo norte americano reflete a tendência ao intercâmbio cultural potencializada pela globalização, e estimula a reflexão sobre a contemporaneidade de Shakespeare.

Hamlet é um dos textos teatrais mais frequentemente encenados nos palcos ocidentais. Porém, como indica o comentário do crítico Harold Bloom (1995), a sua versão definitiva depende muito do leitor que pode escolher entre o Hamlet do Primeiro (1623), Segundo (1632), Terceiro (1664) e Quarto (1685) Fólios, além dos dois in-quartos. De qualquer modo, Shakespeare (1564-1616) morreu antes de poder ver sua obra publicada e, assim, estas edições não possuem o aval do autor, o que problematiza a expressão "autêntico Shakespeare".

Hamlet é também uma das peças mais filmadas mesmo antes da invenção do cinema falado, o que acentua o problema da expressão "autêntico Shakespeare": deve-se dar privilégio ao enredo, ao texto ou, ainda, às imagens promovidas por ambos? É possível chegar a essas imagens excluindo um ou outro?

\section{Shakespeare no cinema contemporâneo}

E quando Abel Gance, em 1927, proclamou com entusiasmo: "Shakespeare, Rembrandt, Beethoven, farão cinema... Todas as lendas, todas as mitologias e todos os mitos, todos os fundadores de novas religiões, sim, todas as religiões... aguardam sua ressurreição luminosa, e os heróis se acotovelam às nossas portas". WALTER BENJAMIN 
FILGUEIRAS - A tradução intersemiótica de Hamlet, por Michael Almereyda

Shakespeare foi usado pelo cinema para dar consistência e valor aos roteiros filmados, e a peça Hamlet foi adaptada para cerca de 70 versões, desde o cinema mudo. Mas, Richard Burt, professor de inglês na Universidade da Flórida, afirma que, desde a década de 1990, é possível reconhecer certa retomada da obra do bardo em adaptações cinematográficas e, esta é a novidade, sem o tratamento dispensado a um gênio, mas sob o signo do fenômeno que ele denominou glo-cali-zação (glo-cali-zation), ou seja, um duplo colapso do local e do global tendo a Califórnia (ou Hollywood) como centro organizador de tão diferentes referências culturais (Burt, 2003, p. 16). Burt ressalta que a cosmopolita Los Angeles não é exclusivamente americana ou ocidental, e que a Califórnia é um celeiro de diversidade cultural e étnica, desde os subúrbios de Orange County até o centro-sul de Los Angeles. Desse modo, as distinções entre alta e baixa cultura, autêntico e não autêntico, sagrado e profano, não são mantidas e, assim, há desde a sátira ao respeito excessivo pelo inglês até o reconhecimento de sua contemporaneidade. Por exemplo, a heroína da comédia adolescente $^{1}$ Patricinhas de Beverly Hills (dir. Amy Heckerling, 1995) sabe citar Hamlet porque é fã de Mel Gibson e assistiu à versão dirigida por Franco Zeffirelli, em 1990.

A popularização de Shakespeare via mídias eletrônicas foi acompanhada de sua decanonização por uma nova geração de espectadores formados pela cultura da MTV. Em Houve uma vez dois verões (dir. Jorge Furtado, 2002), Juca vai à praia com uma camiseta com o rosto de Shakespeare estampado e avisa ao amigo que esta é a sua estratégia para atrair as garotas. Em Orange County (dir. Jake Kasdan, 2002), o professor de inglês pergunta à turma quem lhes vem à mente quando se fala de Romeu e Julieta e ouve, como resposta, "Claire Danes", seguida do complemento de outro aluno, "Leonardo DiCaprio".

Para Richard Loncraine, "se você está fazendo um filme de Shakespeare para a audiência contemporânea, você tem que ter certeza de que ela não vai se entediar",2 (Loncraine apud Kumpf, 2004, p. 268). Não se pode desconsiderar que há 400 anos as pessoas tinham a poesia e a música das palavras de Shakespeare como fontes de estímulo sensorial, mas hoje os estímulos visuais são muito presentes e limitam o olhar que se acostumou à fluidez de imagens dos filmes. Burt vê no desenvolvimento das mídias

\footnotetext{
${ }^{1}$ Filme inspirado em Emma, de Jane Austen.

${ }^{2}$ Minha tradução. No original: "If you're making a Shakespeare film for a contemporary audience, you have to make sure that they don't get bored".
} 
eletrônicas um espaço de produção de uma nova leitura de Shakespeare porque sua obra tem sido mais vista no cinema do que no teatro e mais na TV do que no cinema. Assim, seu reconhecimento vem através desses novos veículos, ligados a novas formas de vida cujas referências culturais, naturalmente, não são as mesmas do espectador elizabetano. Ele lembra que Shakespeare foi usado como modelo de gênio pelo Império Britânico na colonização dos Estados Unidos, quando colonizadores e colonizados investiam na distinção entre o autêntico e o não-autêntico Shakespeare. Mas, hoje, essa distinção perdeu o sentido.

\section{A relação de valor da obra fonte e sua adaptação}

O tratamento não canônico de Shakespeare abre caminho para a sua popularização através do cinema. Para Burt (2003, p. 16), os conservadores podem achar essas adaptações simplistas, e que os liberais, ao contrário, veriam a popularização da mídia como primeiro passo para o Shakespeare verdadeiro. De qualquer modo, as duas posições concordam que o popular é secundário e têm o mesmo problema: não há mais um modelo de Shakespeare a ser alcançado, "o centro já está descentralizado, o original já é híbrido, o autêntico já é simulacro" (Burt, 2003, p. 17) ${ }^{3}$. Simulacro como uma operação pós-moderna de reprodução que subverte os códigos do seu antecessor, como uma adaptação cuja multiplicidade de referências redireciona o sentido.

Linda Hutcheon lembra que as adaptações não são novidades do nosso tempo, "Shakespeare transferiu histórias da cultura dele da página para o palco e as fez acessíveis para toda uma nova audiência" (Hutcheon, 2006, p. 2) ${ }^{4}$. Para a autora, a contemporaneidade herdou o mesmo hábito de adaptar, mas tem-se muito mais matérias à disposição. Assim como Burt, Hutcheon se opõe às críticas universitárias e jornalísticas que tratam as adaptações do cinema popular como produto secundário em qualidade.

\section{O Hamlet de Almereyda}

\footnotetext{
${ }^{3}$ Minha tradução. No original: "the center is already decentered, the original is already hybrid, the authentic is already a simulacrum".

${ }^{4}$ Minha tradução. No original: "Shakespeare transferred his culture's stories from page to stage and made them available to a whole new audience".
} 
FILGUEIRAS - A tradução intersemiótica de Hamlet, por Michael Almereyda

As adaptações cinematográficas de Shakespeare da última década seguiram pelo menos três tendências: o zelo respeitoso na tentativa de se aproximarem de um ideal de original que relaciona Shakepeare a um lugar de destaque na crítica; a atualização das peças através do uso de sua palavra em um cenário contemporâneo e, finalmente, a atualização dos temas e das linhas do autor. O Hamlet (dir. Almereyda, 2000) reúne-se a Romeu e Julieta (1996, dir. Baz Luhrmann) na apropriação das peças de Shakespeare, palavras ou temas, por um cinema interessado em uma audiência que tem a tecnologia infiltrada no seu estilo de vida, ouve música eletrônica em iPhones e assiste a filmes baixados na internet.

Conforme afirma no prefácio ao roteiro do filme (Almereyda, 2000, p.3), sob influência da leitura Shakespeare, Our Contemporary, de Ian Kott, Michael Almereyda quis dar à sua adaptação o rosto do fim do século XX, um corpo vivo para o príncipe da Dinamarca, e encontrou no ator Ethan Hawke um parceiro para essa jornada. Os dois concordavam com o Holden Caulfield (personagem de $O$ apanhador no campo de centeio, de J. D. Salinger) sobre a interpretação de Sir Laurence Olivier (Hamlet, 1948); era muito boa de se ver, mas, conforme Caulfield, "ele parecia muito mais uma droga de um general do que um cara atormentado" (Salinger, 1999, p. 13). Para Almereyda e Hawke, Hamlet é alguma coisa entre James Dean e Kurt Cobain - ou um novo modelo de Sir: Mick Jagger.

Depois de abandonar o curso de História da Arte, na Universidade de Harvard, Michael Almereyda filmou três adaptações literárias antes de Hamlet: o curta metragem $A$ Hero of Our Time (1985), de Michail Lermontov, Twister (1989), baseado em Oh!, de Mary Robinson e o curta metragem The Rocking Horse Winner (1997), de D. H. Lawrence. $\mathrm{O}$ que marca o trabalho do autor é a liberdade no tratamento dado tanto às referências adquiridas pela universidade quanto às formadas pela televisão. Na adaptação de Hamlet, a sinopse deve informar que Hamlet, o presidente do conglomerado econômico Dinamarca morre e seu irmão Cláudio assume as empresas, que disputam mercados com a Noruega, outra corporação. Cláudio se casa com Gertrudes, sua cunhada. Hamlet, o sobrinho, não aceita o casamento e recebe a visita do fantasma de seu pai revelando que foi assassinado e que ele espera por vingança. O filho do poderoso empresário Hamlet é um jovem em torno dos 27 anos de idade, estudante de cinema não interessado pelos negócios da família. Ele quer ter certeza de que o fantasma de seu pai lhe fala a verdade e filma aquilo que lhe fora narrado para que, através do espelho que a representação é, Cláudio se reconheça e 
FILGUEIRAS - A tradução intersemiótica de Hamlet, por Michael Almereyda

confirme as suspeitas. Quando isso acontece, Hamlet parte para a ação: "Se for agora, não está para vir; se não está para vir, é esta a hora; e se essa é a hora virá de qualquer modo" (Shakespeare, 1979, p. 318).

Diferentemente do seu pai guerreiro, o príncipe intelectual Hamlet não é pragmático, e o desenvolvimento da peça leva à morte de todos, exceto a de Horácio, personagem que o autor nos deixa como o narrador da tragédia e, na versão de Almereyda, como matéria de jornal de TV. Nos cortes do texto transposto para imagens, sente-se a mão do diretor Michael Almereyda manipulando a peça para contextualizá-la, e Hamlet deixa de escrever uma peça para editar seu filme. Assim, a adaptação dialoga com o lugar de Shakespeare na tradição literária ocidental, com relações entre teatro e cinema, arte e cultura de massa, modernismo e pós-modernismo, e faz da peça elizabetana um filme entre o hollywoodiano e o independente 5 .

Hamlet foi lançado em janeiro de 2000, no Sundance Film Festival, festival de cinema independente e foco de interesse dos grandes estúdios, compradores dos direitos de distribuição de filmes que fogem dos padrões dos blockbusters e são direcionados a uma audiência atualizada com as pesquisas das vanguardas artísticas. Desde então Almereyda teve que corrigir aqueles que viam no excesso de logomarcas o oportunismo dos patrocinadores; ironicamente, ele precisou pagar para fazer uso do logotipo, por exemplo, da Pepsi. O diretor queria reafirmar em imagens a prisão que a Dinamarca é e, para refletir o mundo da sociedade de consumo, inundou a tela com os excessos do marketing e suas correntes que definem o cenário urbano e fazem parte da bagagem de referências culturais contemporâneas. $\mathrm{O}$ exagero da publicidade encurrala o indivíduo através do exercício de operação de uma lógica excêntrica que considera privilégio ser associado a certa marca (claro que, nesse contexto, uma marca passa a significar mais do que um refrigerante, seu valor se refere às imagens criteriosamente associadas a ela).

A Manhattan de Almereyda está cercada por espelhos, ela é o lugar da imagem refletida seja por óculos escuros, seja por vidros de limusines; ela é o lugar da reprodução por câmeras de segurança ou por lentes fotográficas. Apontar a valorização da imagem e de sua reprodução é a pista do filme para a primeira linha da peça Hamlet, "quem está aí?". Não é com ela que o diretor inicia a sua adaptação (Almereyda fez testes com a audiência e

\footnotetext{
${ }^{5}$ Ainda que seja um filme independente que se passa em NY, foi distribuído pela Miramax.
} 
FILGUEIRAS - A tradução intersemiótica de Hamlet, por Michael Almereyda

sentiu que era necessário mudar a estrutura da peça para antecipar a aparição do protagonista), mas é essa a pergunta que o orienta, a relação entre ser e parecer.

O filme é iniciado por sequência cujo ângulo é bastante representativo da posição do olhar do ser humano para as construções humanas: como se estivéssemos deitados sendo conduzidos, entre anúncios publicitários gigantescos, ao contexto da excessiva intromissão do mercado na paisagem da cidade. Em vez da pergunta "quem está aí?" do guarda Bernardo, textos impressos no estreito leito que resta de céu entre os altos edifícios, a cidade é mostrada sob as linhas que descrevem a situação, Cláudio é o novo presidente da Dinamarca e vai se casar com Gertrudes. Ao som de Let me see, Morcheeba, Hamlet aparece pela primeira vez, em meio a Times Square, seus outdoors e o Hotel Elsinore.

O inglês shakespeariano de mais de quatro séculos estimula a criação daquele entrelugar de variadas percepções sobre o contexto de excessiva publicidade e uso de tecnologia na vida contemporânea, uma leitura crítica que não deixa de dar ao espectador o prazer da fluidez que os recursos de som e imagem proporcionam. Almereyda transforma o intelectual de Wittenberg em estudante de cinema, frequentador da gigante locadora de vídeos Blockbuster, e é construída uma relação paradoxal, pois, ao distanciar-se do contexto cultural de Shakespeare, o diretor aproxima-se do caráter de Hamlet, traduzindo-o. E o personagem também tece a relação contemporânea com a obra, pois, em seu apartamento, Hamlet assiste e edita as imagens de Hamlet, com o ator sir John Gielgud; o Hamlet de Almereyda não ignora a existência de Hamlet.

O estilo da interpretação de Ethan Hawke é representativo dessa sensibilidade que a enorme tela do cinema pode proporcionar: a riqueza minimalista alcança o tamanho ideal quando projetada ali. Proponho uma comparação entre a versão almereydiana e a de Laurence Olivier (Hamlet, dir. Laurence Olivier, 1948), para a cena em que Hamlet e o fantasma do seu pai se encontram, pois acredito que, além da distância do tempo, pode-se perceber a influência da tradição teatral dos palcos de Old Vic na adaptação inglesa ${ }^{6}$, o que afasta o espectador contemporâneo que a ignora.

Assim, o Hamlet de Laurence Olivier encontra o fantasma de seu pai no alto de uma torre de vigília, em um castelo medieval, envolto por fumaça muito usada nos palcos e no cinema com o objetivo de criar atmosfera apreensiva. Aqui, esta fumaça não só acentua o

\footnotetext{
${ }^{6}$ Não se afirma que se trata de "teatro filmado", já que é visível a expansão dos limites do palco neste Hamlet.
} 
FILGUEIRAS - A tradução intersemiótica de Hamlet, por Michael Almereyda

caráter sobrenatural do encontro como impede a visão do rosto do rei assassinado (o ator não tem seu nome creditado) - a falta de nitidez ativa a imaginação do espectador. Ao contrário, Almereyda nos dá o rosto do pai de Hamlet (Sam Shepard), e a única fumaça que se aproxima dele é a de seu cigarro. O espectador de cinema narrativo exige realismo, mesmo em filmes que tratam do fantástico, e Almereyda precisou materializar o encontro fortalecendo os laços entre pai e filho, subjetivando a relação através da aproximação dos personagens. Hamlet (Shepard) toca em Hamlet (Hawke), ele não é um fantasma, é o pai morto, diante de um filho amedrontado por suas revelações que, como se sabe, o chamam a pôr ordem no mundo. "Lembre-se de mim" é dito em meio a um abraço precedido por um olhar tomado pelas saudades próprias de um filho que ama seu pai.

Depois de pedir vingança, o fantasma fuma um cigarro e é visto na varanda através da transparência presente dos vidros das janelas por Horácio e Marcela: "Dê boas vindas ao estranho", diz Hamlet. Não é difícil encontrar o estranho em Times Square, entre tanta diversidade e luzes piscando para o consumo de produtos descartáveis. As propagandas são as obras de arte que cercam o Hotel Elsinore; enquanto no quarto de Hamlet as paredes têm pôsters de Nietzsche, Ofélia lê William Burroughs: a individualidade modernista foi encurralada pela expansão do marketing e de sua retórica, que é uma apropriação das pesquisas vanguardistas com a ideologia de gerar capital, em sentido oposto a partir de um mesmo formato.

Talvez a imensa fragmentação e privatização da literatura moderna - sua explosão numa multiplicidade de estilos e maneirismos particulares distintos — pronuncie tendências mais profundas e mais gerais da vida social como um todo. E se supuséssemos que a arte moderna e o modernismo - longe de serem um tipo de curiosidade estética especializada - realmente antecipam tendências sociais dentro dessa linha? E se supuséssemos que, nas décadas decorridas desde a emergência dos grandes estilos modernos, a própria sociedade começou a fragmentar-se dessa maneira, cada grupo passando a falar uma curiosa língua particular própria (...)? Nesse caso, porém, a própria possibilidade de qualquer norma lingüística nos termos da qual fosse possível ridicularizar as línguas particulares e os estilos idiossincráticos desapareceria, e não teríamos nada além da diversidade e da heterogeneidade estilísticas. (Jameson, 1993, p. 29)

Jameson explica que é nesse momento, em que a multiplicidade de referências retira a chance de se ter um paradigma, que o pastiche aparece e não há mais lugar para a paródia. Como o pastiche não carrega consigo um modelo com o qual se contraponha ao imitado, sua mímese não critica aquilo que copia. É uma cópia vazia, "sem aquele sentimento ainda 
FILGUEIRAS - A tradução intersemiótica de Hamlet, por Michael Almereyda

latente de que existe algo normal" (Jameson, 1993, p. 29). Conforme Jameson, a exploração da individualidade foi levada ao extremo com o modernismo e, para o pósmodernismo, não teria restado nenhuma ruptura, apenas a singularidade de combinações no re-visitar do passado. E Jameson lembra que esse passado "é menos nosso passado histórico do que nossas idéias ou estereótipos culturais sobre esse passado" (Jameson, 1993, p. 34) e, se há ainda algum realismo, ele está no choque entre o confinamento no passado e o reconhecimento de que "parecemos condenados a buscar o passado histórico através de nossas próprias imagens e estereótipos pop sobre esse passado" (idem). Essa descontinuidade também é percebida por Terry Eagleton, que fala da modernidade como o momento em que o conhecimento foi afastado de sua relação com a ética e a estética, estas também desligadas entre si, reverberando a posição de Adorno e Horkheimer acerca dos excessos do pensamento iluminista.

A serpente entra no Paraíso; a classe média começa a ascender; os pensamentos se separam dos sentimentos; ninguém consegue mais pensar com as pontas dos dedos; e a história deslancha até Mr. George Bush. As três grandes áreas da vida histórica - o conhecimento, a política e o desejo - são descoladas uma da outra; cada uma se torna especializada, autônoma, fechada em seu próprio espaço. O conhecimento se desliga de suas restrições éticas e começa a operar a partir de leis próprias, internas e autônomas. Com o nome de ciência, não mantém mais nenhuma relação óbvia com o ético e o estético, e assim começa a perder o contato com o valor. (Eagleton, 1990, p. 264)

Para essa sociedade com valores alienados entre si, a arte é "algo meramente suplementar" (Eagleton, 1990, p. 264). Como mercadoria liberada das funções sociais tradicionais, a arte ganhou "a liberdade anônima do mercado" (p. 265), mas perdeu a sua antes necessária relação com a ética e o conhecimento. Esse desligamento merece atenção porque a arte, ao mesmo tempo em que é uma região marginal da racionalidade, pode funcionar como "espécie de válvula de segurança ou sublimação dessas áreas potencialmente perigosas da psique" (Idem) e, assim, servir para propósitos políticos de regimes totalitários.

Sugiro que, na adaptação almereydiana, há a ilustração da noção de pastiche de Jameson, pois Hamlet (que está em torno dos 30 anos de idade e, portanto, nasceu na década de 1970) utiliza, em seu filme dentro do filme, imagens que remetem à clássica família dos anos 1950, símbolo do American way of life, para mostrar a harmonia de um lar 
FILGUEIRAS - A tradução intersemiótica de Hamlet, por Michael Almereyda

em referência não à sua experiência, ao seu passado, mas à ideia formada por campanhas publicitárias de eletrodomésticos e afins, ou seja, ao imaginário de um passado construído por uma cultura cada vez mais constituída por elementos do processo de industrialização.

A tecnologia cria um novo tecido de memória a partir do documento manipulável por programas de correção e criação, enquanto a obsessão pela imagem e pelo potencial de manipulá-la produz novos discursos e inventa realidades. Hamlet absorve inserções de trechos em vídeo, de imagens de monitores...; a exposição dos suportes enriquece a pluralidade visual que nutre esse filme e estimula o pensar sobre ser/parecer. O suicídio de Ofélia, por exemplo, é antecipado por Almereyda em uma das cenas mais bonitas do filme; enquanto Polônio descreve, com mais arte do que fatos, a sua tese para a aparente loucura de Hamlet (a paixão por Ofélia), ela é atormentada por um desejo de morte que se realizará depois do assassinato acidental de seu pai por Hamlet. O mergulho na piscina se efetiva na fonte do Museu Guggenheim, a água refletora do grande espelho que circunda Manhattan afoga a personagem, que não consegue suportar enxergar a sua situação: as circunstâncias da morte do pai e o fim do primeiro amor.

No encontro em que Ofélia entrega a Hamlet os presentes que recebeu dele, o diálogo do casal é ouvido não atrás de cortinas como fazem os personagens da peça, mas pela gravação do microfone que Polônio, Gertrudes e Cláudio fazem Ofélia usar. Hamlet descobre o aparelho escondido enquanto diz para ela:

... sou relativamente honesto e, contudo, de tais coisas poderia acusar-me, que melhor seria que minha mãe não me tivesse posto nesse mundo. Sou muito orgulhoso, vingativo, ambicioso, com mais pecados na cabeça do que pensamentos para concebê-los, fantasias para dar-lhes forma ou tempo para executá-los. (Shakespeare, 1979, p. 254)

As cenas seguintes mostram a intensidade do envolvimento dos dois; a fala de Hamlet continua em off na mensagem que deixa na secretária eletrônica de Ofélia, "vá para o convento" - sendo que, como explica a nota da tradução brasileira de Cunha Medeiros e Oscar Mendes, "nunnery tem em gíria também o sentido de prostíbulo, e parece que Hamlet tem em espírito esse sentido" (Shakespeare, 1979, p. 254). Enquanto ouve a voz gravada de Hamlet e queima fotos suas diante de um espelho, Ofélia começa a enlouquecer, processo que explode com a morte de Polônio, em que a fixação de Almereyda por espelhos também 
FILGUEIRAS - A tradução intersemiótica de Hamlet, por Michael Almereyda

está presente: Hamlet atira contra sua imagem refletida no espelho da porta do armário, e não é Cláudio quem a bala encontra.

A morte de Polônio e a loucura e suicídio de Ofélia revoltam Laertes, que desafia Hamlet. A cena final da luta foi mantida como uma disputa de esgrima, mas um revólver aparece pela sexta vez no filme ${ }^{7}$, entre as quais nas três últimas também não há ocorrência na peça. A belicosidade contemporânea duplica o uso do símbolo de violência no filme: cenas da guerra da Bósnia são exibidas durante o monólogo em que Hamlet é "apresentado", logo no início do filme; em um trecho em que a pergunta "ser, ou não ser?" é antecipada como fala de Hamlet diante de uma câmera mirando uma arma para o próprio rosto. O Hamlet de Almereyda capta o espírito da época através de Shakespeare e da cidade, e transmite para a audiência o estilo de vida dos moradores de Elsinore.

Elvis Mitchell, em crítica para o New York Times, elogia o uso da cidade e a apropriação da tecnologia presente no cotidiano dos grandes centros: "NY se transforma em um personagem complexo neste filme vital e agudamente inteligente" 8 . Para ele, Hamlet "é sobre isolamento urbano e o dano que isso causa" ${ }^{9}$; a cidade oprime com suas câmeras e transparências, e o único momento em que se vê um ambiente não urbano, com alguma natureza, é na cena do enterro de Ofélia. "Hamlet é um acerto palpável. Ou deveria ser" ${ }^{10}$. Para o crítico, "Almereyda criou um novo modelo para adaptações de Shakespeare, começando pelo entendimento emocional do material que corresponde ao novo período e à locação.” E aproveita para criticar a estilização da adaptação para Romeu e Julieta, de Baz Luhrmann.

A comparação feita por Mitchell entre Hamlet, de Almereyda, e Romeu + Julieta (1996), de Baz Luhrmann, é natural: dois diretores nascidos no começo da década de 1960, em países que foram colonizados pelo Império Britânico, filmando as palavras de Shakespeare no final da década de 90 em um cenário contemporâneo, com um elenco conhecido por uma audiência não especializada no autor inglês e formada por referências da cultura de massa. Não vou me ater à comparação de Mitchell, mas gostaria de apontar

\footnotetext{
${ }^{7}$ Antes, na cena em que Hamlet não mata Cláudio depois de ele se confessar; a morte de Polônio; a filmagem de trechos do "ser ou não ser" com uma arma apontada para cabeça; cena em que Hamlet invade o escritório de Cláudio, mas não o encontra, Cláudio mostra a Laertes a arma com a qual Hamlet pretendia matá-lo

${ }^{8}$ Minha tradução. No original: "New York becomes a complex character in this vital and sharply intelligent film."

${ }^{9}$ Minha tradução. No original: "'Hamlet' is a movie about urban isolation and the damage it causes,

${ }^{10}$ Minha tradução. No original: "'Hamlet' is a palpable hit, or it should be."
} 
FILGUEIRAS - A tradução intersemiótica de Hamlet, por Michael Almereyda

que sua preferência por Almereyda se deve tanto ao excelente uso da cidade como pelo maior aproveitamento de cada quadro: a fragmentação de Hamlet também se comunica com a geração formada pela MTV.

A rica colcha de retalhos é costurada não apenas pelo texto como também por referências visuais e sonoras; no roteiro, por exemplo, Almereyda afirma que pensava em filmar o monólogo "Ser ou não ser" como filmou, entre os corredores do gênero Ação de uma locadora Blockbuster, mas gostaria de inserir trechos que teriam sido gravados na vídeo-instalação do artista Bill Viola, no Whitney Museum, porém imprevistos o impediram. A idéia era deixar o monólogo espremido entre duas percepções de arte, duas diferentes formas de representação. Ainda que essa versão não tenha sido filmada, Hamlet quer estar no entre-lugar de extremos de compreensão de mundo.

O filme também circula entre percepções através da homenagem que presta ao finlandês Hamlet vai à luta (dir. Aki Kaurismaki, 1987) e a James Dean. Na peça, Hamlet aconselha os atores para que obtenham melhores efeitos com a representação que encena a morte do rei por envenenamento. Esse momento é muito importante porque é ali que Hamlet se emociona com o poder de fingimento do ator e do poder de criar realidades através da sua representação, como observa Goethe sobre a cena ii, ato II:

O homem que declama com tanta emoção pessoal a morte de Príamo causa ao próprio príncipe uma profunda impressão; ele desperta a consciência do jovem hesitante e, assim, essa cena torna-se prelúdio daquela em que o pequeno espetáculo faz um tão grande efeito sobre o rei. Hamlet sente-se envergonhado pelo ator que toma tão grande parte num sofrimento alheio, fingido e, devido a isso, desperta nele imediatamente a idéia de fazer desse mesmo modo uma tentativa sobre a consciência de seu padrasto. (Goethe, 1998, p. 34)

No filme, Almereyda cortou todo o texto do aconselhamento substituindo-o por imagens de James Dean. Enquanto Hamlet fala “o que é Hécuba pra ele ou ele pra Hécuba?", vemos Dean em Vidas amargas (dir. Elia Kazan, 1955) e sua famosa interpretação influenciada pelo Método de Stanislavski que, assim como sugere Hamlet, procura adequar a palavra à ação, imprimindo naturalidade. A homenagem a Kaurismaki vem através de um pato de brinquedo que Ofélia devolve junto a outros presentes de Hamlet, pois, em seu filme sarcástico, a disputa dos conglomerados é pelo monopólio mundial dos patos de plástico. Assim, com o uso de múltiplas referências culturais e de 
FILGUEIRAS - A tradução intersemiótica de Hamlet, por Michael Almereyda

diferentes veículos, Michael Almereyda interpretou Hamlet como ator que aceitou as recomendações do príncipe dinamarquês e, desse modo, fez de seu filme resumo e breve crônica do nosso tempo.

\section{Referências:}

ALMEREYDA, Michael. Hamlet's screenplay. Nova York: Faber and Faber, 2000.

BENJAMIM, Walter. Trad. S. P. Rouanet. Obras Escolhidas. São Paulo: Ed. Brasiliense, 1985.

BLOOM, Harold. Trad. Marcos Santarrita. O cânone ocidental - os livros e a escola do tempo. Rio de Janeiro: Ed. Objetiva, 1995. . Shakespeare, a invenção do humano. Trad. José Roberto O'Shea. Rio de Janeiro: Ed. Objetiva, 2000.

BOOSE, Lynda; BURT, Richard. Shakespeare - The Movie II (Popularizing the Plays on Film, TV, Video, and DVD). Nova York: Routledge, 2003.

EAGLETON, Terry. Trad. Mauro Sá Rego Costa. A ideologia da estética. Rio de Janeiro: Jorge Zahar Editor, 1990.

GOETHE, J. W. Trad. João Osório de Castro. Anos de aprendizagem de Wilhelm Meister. Lisboa: Relógio D’Água Editores, 1998.

HUTCHEON, Linda. A Theory Of Adaptation. Nova York: Routledge, 2006.

JAMESON, Fredric. Trad. V. Ribeiro. O pós-modernismo e a sociedade de consumo. In: KAPLAN, E. Ann (Org.): O mal-estar no pós-modernismo. Rio de Janeiro: Jorge Zahar Editor, 1993.

KOTT, Ian. Shakespeare, Our Contemporary. Londres: Ed. Methuen, 1967.

KUMPF, Robert. Theater and Film: A Comparative Anthology. New Haven: Yale University Press, 2004.

SALINGER, J. D. Trad. Álvaro Alencar, Antônio Rocha e Jório Dauster. O apanhador no campo de centeio. Rio de Janeiro: Ed. do Autor, 1999.

SHAKESPEARE, William. Hamlet. In: The Complete Works of William Shakespeare. Londres: Gramercy Books, 1990. 
FILGUEIRAS - A tradução intersemiótica de Hamlet, por Michael Almereyda . Hamlet. Trad. F. Carlos de Almeida Cunha Medeiros e Oscar Mendes. São Paulo: Ed. Abril, 1979. 